\title{
Influence of welding parameters on electromagnetic supported degassing of die- casted and wrought aluminum
}

Cite as: J. Laser Appl. 32, 022031 (2020); https://doi.org/10.2351/7.0000064

Submitted: 01 April 2020. Accepted: 01 April 2020. Published Online: 29 April 2020

André Fritzsche, Kai Hilgenberg (iD), and Michael Rethmeier (iD)

\section{COLLECTIONS}

Paper published as part of the special topic on Proceedings of the International Congress of Applications of Lasers \& Electro-Optics (ICALEO<sup>\&\#174; </sup> 2019)

Note: This paper is part of the Special Collection: Proceedings of the International Congress of Applications of Lasers

(B)

\& Electro-Optics (ICALEO 2019).
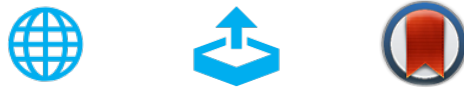

\section{ARTICLES YOU MAY BE INTERESTED IN}

Mathematical modeling of the geometrical differences between the weld end crater and the steady-state weld pool

Journal of Laser Applications 32, 022024 (2020); https://doi.org/10.2351/7.0000068

Theoretical study of influence of electromagnetic stirring on transport phenomena in wire feed laser beam welding

Journal of Laser Applications 32, 022026 (2020); https://doi.org/10.2351/7.0000069

On the influence of $\mathrm{TiB}_{2}, \mathrm{TiC}$, and TiN hard particles on the microstructure of localized laser dispersed AISI D2 tool steel surfaces

Journal of Laser Applications 32, 022028 (2020); https://doi.org/10.2351/7.0000059

\section{Sellight Highlights of the best new research} in the physical sciences 


\title{
Influence of welding parameters on electromagnetic supported degassing of die-casted and wrought aluminum
}

Cite as: J. Laser Appl. 32, 022031 (2020); doi: 10.2351/7.0000064

Submitted: 1 April 2020 - Accepted: 1 April 2020 .

Published Online: 29 April 2020

André Fritzsche, ${ }^{7}$ Kai Hilgenberg, ${ }^{1,2}$ (iD and Michael Rethmeier ${ }^{1,2}$ (D)

\author{
AFFILIATIONS \\ ${ }^{1}$ BAM Federal Institute for Materials Research and Testing, Unter den Eichen 87, 12205 Berlin, Germany \\ ${ }^{2}$ Institute of Machine Tools and Factory Management, Technical University Berlin, Pascalstraße 8-9, 10587 Berlin, Germany
}

Note: This paper is part of the Special Collection: Proceedings of the International Congress of Applications of Lasers \& ElectroOptics (ICALEO $\left.{ }^{\circledR} 2019\right)$

\begin{abstract}
Laser beam welding of aluminum die casting is challenging. A large quantity of gases (in particular, hydrogen) is absorbed by aluminum during the die-cast manufacturing process and is contained in the base material in solved or bound form. After remelting by the laser, the gases are released and are present in the melt as pores. Many of these metallurgic pores remain in the weld seam as a result of the high solidification velocities. The natural (Archimedean) buoyancy is not sufficient to remove the pores from the weld pool, leading to process instabilities and poor mechanical properties of the weld. Therefore, an electromagnetic (EM) system is used to apply an additional buoyancy component to the pores. The physical mechanism is based on the generation of Lorentz forces, whereby an electromagnetic pressure is introduced into the weld pool. The EM system exploits the difference in electrical conductivity between poorly conducting pores (inclusions) and the comparatively better conducting aluminum melt to increase the resulting buoyancy velocity of the pores. Within the present study, the electromagnetic supported degassing is investigated in dependence on the laser beam power, welding velocity, and electromagnetic flux density. By means of a design of experiments, a systematic variation of these parameters is carried out for partial penetration laser beam welding of $6 \mathrm{~mm}$ thick sheets of wrought aluminum alloy AlMg3 and die-cast aluminum alloy AlSi12(Fe), where the wrought alloy serves as a reference. The proportion of pores in the weld seams is determined using x-ray images, computed tomography images, and cross-sectional images. The results prove a significant reduction of the porosity up to $70 \%$ for both materials as a function of the magnetic flux density.
\end{abstract}

Key words: laser beam welding, electromagnetic supported degassing, die-casted aluminum

Published under license by Laser Institute of America. https://doi.org/10.2351/7.0000064

\section{INTRODUCTION}

The concept of weight reduction is important in many industries. In particular, in the automotive industry and in the aerospace industry, this idea is strongly associated with the use of aluminum alloys. The die casting process offers the possibility of producing load-adapted and complex components with good dimensional accuracy. However, the die casting mold is quickly filled with molten aluminum in this manufacturing process, whereby organic release agents and other impurities are introduced into the die casting component as a result of the occurring turbulences. ${ }^{1}$ These are initially unproblematic, as they are almost completely precipitated in the form of hydrides during casting production due to the low cooling speeds. However, these hydrogen compounds are a great challenge for the subsequent joint welding of die-cast aluminum components. In the course of the welding process, the hydrides dissolve and release hydrogen. The hydrogen then diffuses into areas of higher temperature ${ }^{1}$ and is present in the melt in the form of small gas bubbles. The solidification rate during welding is significantly higher than during casting. In addition, the hydrogen solubility of aluminum decreases with declining temperature, and at the phase transition from liquid to solid, a 20 -fold increase in solubility (for pure aluminum) occurs. As a result, the hydrogen does not have sufficient time to transform to hydrides. ${ }^{2}$ 
A further aspect of partial penetration laser beam welding is the occurrence of keyhole instabilities, which can cause the formation of process pores near the keyhole tip during the solidification process. ${ }^{3}$ Process pores and metallurgical (hydrogen-related) pores lead to a reduction of strength of the welded joint. Therefore, pressure welding processes like friction stir welding are used. However, friction stir welding of complex aluminum die-cast components is difficult, since the high process forces necessitate the design of complex clamping fixtures.

For fusion welding, the porosity problem has been well solved so far by metal inert gas welding (MIG) or tungsten inert gas welding (TIG) welding, in which the degassing behavior has been improved by selecting low welding velocities. Nevertheless, the associated high energy input into the component leads to distortion and to a broad heat affected zone. With regard to these negative properties and under additional consideration of economic aspects (automatability, process speed, etc.), laser beam welding offers a promising alternative to conventional welding processes. ${ }^{5}$ However, when using this process, modifications are necessary in order to meet the challenges of pore formation during the welding of aluminum die casting alloys.

There are two main approaches for porosity reduction. On the one hand, the natural buoyancy caused by the difference in density between pores and molten metal is supported by extending the existence of the molten bath over time. This has been demonstrated successfully using a laser hybrid method $^{2}$ and a beam oscillation. ${ }^{6}$ However, the temporal prolongation of the weld pool existence is to a certain extent accompanied by the negative properties mentioned above with regard to distortion and heat input. The second approach to porosity reduction is to actively support the buoyancy behavior of the pores. Teichmann et al. ${ }^{1}$ were able to achieve this by welding under reduced ambient pressure. Another innovative method is the usage of an electromagnetic (EM) system to increase the resulting buoyancy velocity of the pores. ${ }^{7,8}$ In addition to the lower density, the lower electrical conductivity $\sigma$ of the pores, compared to the molten aluminum, is exploited. This is achieved by means of a magnetic field oscillating between two magnetic poles located on the left and right above the weld pool (see Fig. 1). The alternating magnetic flux density $B$ perpendicular to the welding direction is technically implemented by the air gap between the magnetic poles. This leads to the formation of eddy currents $j$ parallel to the welding direction whose direction alternates depending on $B$. The resulting Lorentz force $F_{\mathrm{L}}$ is always directed downward and presses the electrically well conductive aluminum melt to the bottom of the weld pool. In addition to the natural, density-induced buoyancy, an electromagnetic buoyancy component is created. The buoyancy force $F_{\mathrm{A}}$ composed of these two parts leads to the removal of gas bubbles. Figure 1 shows the main influencing parameters, which influence the formation and elimination of pores. The formation of pores is mainly determined by the base material and the laser beam welding process. As a result of the die casting process, there are casting defects and impurities in the material. These appear in the form of gas bubbles, hydrides, etc. The hydrogen content can be characterized by the density index (among other things). The process parameters (welding velocity $u_{\text {weld }}$, laser beam power $P_{\mathrm{L}}$, etc.) of the laser beam welding in combination with the material properties (absorption coefficient, thermal conductivity, etc.) determine the weld pool geometry as well as the point of origin of the process pores and metallurgical pores. In addition, the geometric boundary conditions for porosity elimination are defined. Depending on the laser power and the welding speed, a certain weld pool length and depth as well as the solidification velocity of the weld pool results, which limits the time for pore buoyancy. In contrast to this, the electromagnetic influence of the weld pool supports the elimination of pores. In previous investigations, Fritzsche et al. found out in laser beam welding of the aluminum die casting alloy AC-AlSi9MnMg (Silafont 36) that a variation in the frequency of the oscillating magnetic field $f$, which influences the skin depth $\delta$, does not indicate a clear trend regarding to porosity reduction. The initiated electromagnetic pressure was

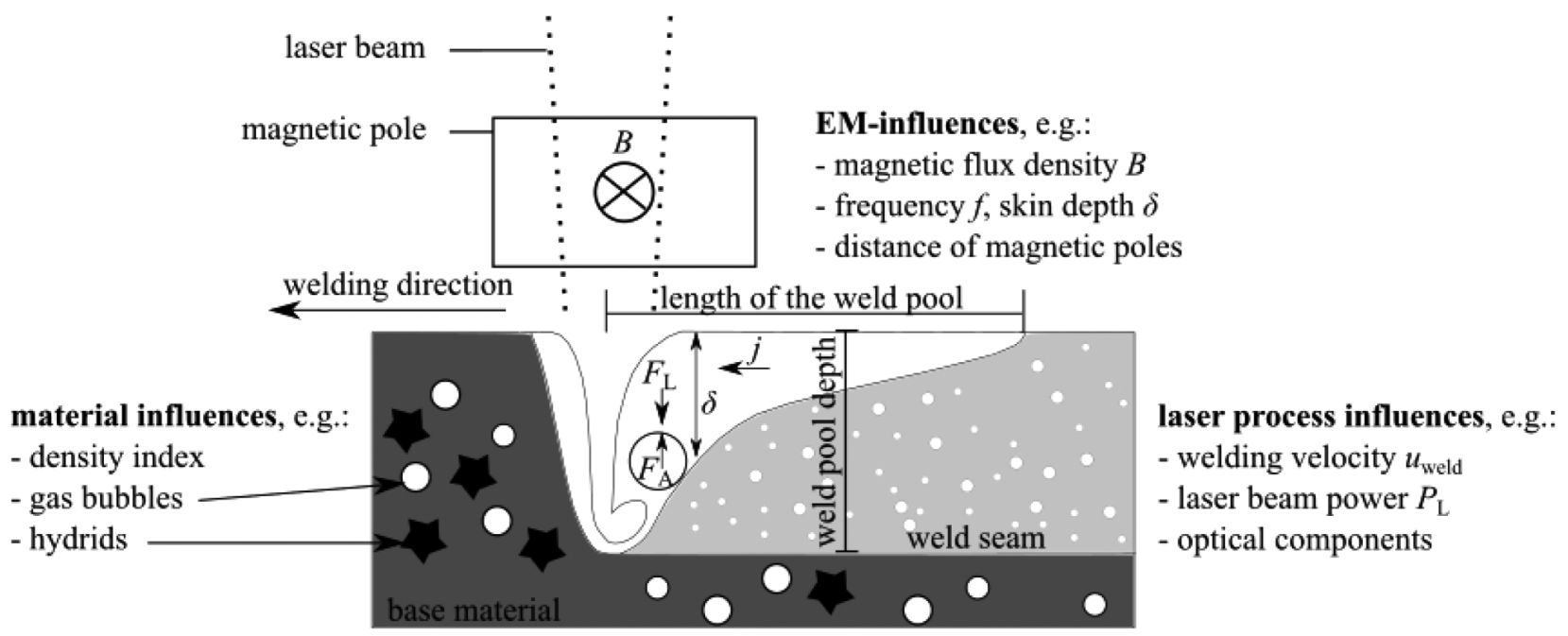

FIG. 1. Influencing factors and functional principle of the electromagnetic porosity reduction at partial penetration laser beam welding. 
TABLE I. Selected parameters of the manufacturing process of aluminum die casting AlSi12(Fe).

\begin{tabular}{lc}
\hline \hline Material/brand name & AlS12(Fe)/230 D \\
Release agent & Safety-Lube 7477 \\
Mixing ratio & $1: 100$ \\
Piston lubrication & Power-Lube 824 \\
Density index & $4.2 \%$ \\
Mold temperature & $250{ }^{\circ} \mathrm{C}$ \\
Piston temperature & $20{ }^{\circ} \mathrm{C}$ \\
Oven temperature & $740{ }^{\circ} \mathrm{C}$ \\
Vacuum & Without vacuum \\
\hline
\end{tabular}

identified as the decisive component for porosity elimination. ${ }^{7}$ The magnetic pressure $p_{\mathrm{m}}$ can be calculated according to

$$
p_{\mathrm{m}}=\frac{B^{2}}{\left(2 \mu_{0}\right)}
$$

where in the welding process, it is controlled via $B$, the magnetic flux density. $\mu_{0}\left(=4 \pi \times 10^{-7} \mathrm{~N} \mathrm{~A}^{-2}\right)$ is the magnetic field constant. This pressure also propagates at weld pool depths that exceed the frequency-dependent skin depth. It is, therefore, assumed that the initiated pressure is also the main influencing factor for porosity reduction at higher laser intensities and deeper weld pools. ${ }^{7}$ In the present study, this aspect is specifically investigated in partial penetration laser beam welding of the aluminum die casting alloy AlSi12 (Fe). The background of this systematic investigation is that an adaptation of the process parameters is necessary for practical, real applications, e.g., by changing component geometries. The robustness of the EM influence shall be investigated at different welding parameters. Using a design of experiments, the laser beam power, welding velocity, and magnetic flux density are varied. Based on the findings from previous investigations, ${ }^{7,8}$ the frequency is not considered as an influencing variable. The same design of experiments is applied to AlMg3. This wrought aluminum alloy serves as a reference material to compare and interpret the results of this investigation. The criteria and values for the classification of welds with regard to permitted porosity ratios and pore sizes are regulated for aluminum materials in DIN EN ISO 13919-2:2001-12. ${ }^{10}$

\section{EXPERIMENTAL SETUP}

The laser beam welding experiments were carried out on $6 \mathrm{~mm}$ thick sheets of die-cast aluminum alloy AlSi12(Fe) (EN AC-44300) and of wrought aluminum alloy AlMg3 (EN AW-5754). The parameters used for the die casting manufacturing process can be found in Table I. The chemical compositions according to the standard and the values measured by spark emission spectrometry for both materials are listed in Tables II and III Both aluminum alloys are nonhardenable alloys, although they differ greatly in their silicon and magnesium content. AlMg3 is used as a reference material, as good results with respect to electromagnetic porosity reduction have already been demonstrated (see Ref. 11). A pretreatment by pickling or grinding of the aluminum materials was not carried out. Right before the welding process, the sample surface was degreased with ethanol. A schematic illustration of the setup is shown in Fig. 2. The laser beam hits the material surface at an angle of entry of $10^{\circ}$ and is backhand orientated. A ceramic shielding gas nozzle is placed with opposite orientation at an angle of $20^{\circ}$. Argon with a volume rate of $351 \mathrm{~min}^{-1}$ is used to protect the weld pool against the atmosphere.

The welds are performed in flat position in a bead-on-plate configuration by using a fiber laser with a wave length of $1070 \mathrm{~nm}$. The laser optics is a BIMO HP with a focal length of $350 \mathrm{~mm}$ and a laser spot diameter of $0.56 \mathrm{~mm}$. The beam parameter product is $11.5 \mathrm{~mm} \times$ mrad. Laser and magnet are located above the workpiece, and their position to each other is fixed. The laser beam hits the workpiece surface exactly in the center of the $18 \mathrm{~mm}$ wide air gap between the magnetic poles as well as in the middle of the $16 \mathrm{~mm}$ wide magnetic pole (in the $x$-direction) (see Fig. 2). The focus position is kept constant at a level of $-6 \mathrm{~mm}$. Furthermore, the workpiece is attached to an $\mathrm{x}-\mathrm{y}$ positioning stage. By its movement relative to the fixed laser-magnet configuration, the welding velocity is achieved. The vertical clear distance between magnet and workpiece is $2 \mathrm{~mm}$. The generated weld seams have a minimum length of $170 \mathrm{~mm}$. The magnetic field oscillates between the two magnetic poles, which are exactly perpendicular to the welding direction, with a frequency $f$ of $3250 \mathrm{~Hz}$ for the entire measuring series with electromagnetic weld pool influence.

To investigate the effect on porosity, three influencing factors $B, P_{\mathrm{L}}$, and $u_{\text {weld }}$ are varied within the design of experiments. A central composite design (CCD) is used to derive a quantitative model for predicting the porosity fraction in the weld seam based on a function of the three influencing parameters. 0 represents the central point for each influencing factor and is repeated a total of six times. Around this central point, a full-factorial $\left(2^{3}\right)$ experimental design is realized, which consists of eight experiments. This is done symmetrically at the eight corners around the central point. The CCD plan is extended by means of a star design (face centered, $\alpha= \pm 1$ ) in order to be able to estimate additional quadratic terms. ${ }^{14}$ This results in 20 tests each for both aluminum alloys (see Table IV). The coefficients of the variables were determined by multiple linear regression, according to Eq. (2),

$$
\begin{aligned}
\hat{y}= & b_{1} x_{1}+b_{2} x_{2}+b_{3} x_{3}+b_{12} x_{1} x_{2}+b_{13} x_{1} x_{3}+b_{23} x_{2} x_{3} \\
& +b_{11} x_{1}^{2}+b_{22} x_{2}^{2}+b_{33} x_{3}^{2}+k .
\end{aligned}
$$

TABLE II. Chemical composition of AISi12(Fe) (EN AC-44300) according to DIN EN 1706 (Ref. 12) and measured by optical emission spectrometer (OES), data in wt. \%.

\begin{tabular}{lllllllrrr}
\hline \hline & \multicolumn{1}{c}{$\mathrm{Si}$} & $\mathrm{Fe}$ & $\mathrm{Cu}$ & $\mathrm{Mn}$ & $\mathrm{Mg}$ & $\mathrm{Cr}$ & $\mathrm{Zn}$ & $\mathrm{Ti}$ \\
\hline DIN EN 1706 & $10.5-13.5$ & $0.45-0.9$ & 0.1 & 0.55 & 0 & 0 & 0.15 & 0.15 & $\mathrm{Al}$ \\
OES & 13.21 & 0.53 & 0.31 & 0.34 & 0.006 & 0.002 & 0.022 & 0.068 & $\mathrm{Bal}$ \\
\hline \hline
\end{tabular}


TABLE III. Chemical composition of AIMg3 (EN AW-5754) according to DIN EN 573-3 (Ref. 13) and measured by OES, data in wt. \%.

\begin{tabular}{llllllllll}
\hline \hline & $\mathrm{Si}$ & $\mathrm{Fe}$ & $\mathrm{Cu}$ & $\mathrm{Mn}$ & $\mathrm{Mg}$ & $\mathrm{Cr}$ & $\mathrm{Zn}$ & $\mathrm{Ti}$ & $\mathrm{Al}$ \\
\hline DIN EN 573-3 & 0.4 & 0.4 & 0.1 & 0.5 & $2.6-3.6$ & 0.3 & 0.2 & 0.15 & $\mathrm{Bal}$ \\
OES & 0.28 & 0.33 & 0.042 & 0.23 & 3.14 & 0.042 & 0.044 & 0.022 & $\mathrm{Bal}$. \\
\hline \hline
\end{tabular}

The coefficient of determination $\mathrm{R}^{2}$ reflects the quality between the model and the experimental values by determining their deviation from each other [see Eq. (3)]. The closer the value is to 1.0, the better the agreement,

$$
\mathrm{R}^{2}=1-\frac{\sum_{\mathrm{i}=1}^{\mathrm{I}}(\mathrm{y}-\hat{y})^{2}}{\sum_{\mathrm{i}=1}^{\mathrm{I}}(\mathrm{y}-\hat{y})^{2}} .
$$

After conducting the design of experiments, the quantity of porosity was determined by $\mathrm{x}$-ray images in top view and evaluated by using the software IMAGEJ via a threshold method. First, the mean gray value and its standard deviation of the entire sheet were determined. The contour of the weld seam to be evaluated was then traced, and the weld seam was cut using the "Crop"-function. To reduce the image noise, the "Smooth"-function was used to replace each pixel with the average gray value of the surrounding $3 \times 3$ pixel square. A pixel is recognized as a pore when the mean gray value of the sheet minus the standard deviation is exceeded. The minimum pore size is 4 square pixels, which corresponds to a pore area of $0.01 \mathrm{~mm}^{2}$. A value of 0.3 is defined as the minimum roundness $(0 \triangleq$ infinitely elongated polygon and $1 \stackrel{\wedge}{=}$ perfect circle $)$. In addition, the functions "Exclude edges" (dark edge areas caused by the smoothing process are not counted as pore) and "Include holes" (material within a pore is evaluated as belonging to the pore) are used. The $\mathrm{x}$-ray images are evaluated over the whole weld seam length. Subsequently, a $70 \mathrm{~mm}$ long area from the center of the respective weld seam was evaluated by computed tomography (CT)
(100 kV microfocus $\mathrm{x}$-ray source). The used detector is a Dexela 1512NDT CMOS detector with cesium iodide scintillator crystals and a GigE-Interface. Representative parameter combinations of the CCD plan were selected. The pore analysis was carried out using the VG STUDIO software. In order to be able to determine the proportion of pores related to the weld seam volume, cross-sectional images were taken at the two end faces of the separated area of the respective weld seam. The weld pool limitation is not recognizable from the mere CT image, so this step is necessary. In VG STUDIO, a so-called region of interest (ROI) can be defined on the basis of the contour of the crosssectional image and the weld seam length. By superimposing the ROI's, which are based on two cross-sectional images for the respective weld seam, it is possible to determine a meaningful proportion of pores in the weld. The porosity was determined using the VGDefX algorithm. The edge length of a voxel (cube-shaped) is $0.0374 \mathrm{~mm}$, whereby the minimum size of a pore is 8 voxels. This results in a smallest detectable pore diameter of approximately $0.1 \mathrm{~mm}$. In summary, it can be said that the evaluation of the x-ray images determined the pore content related to the weld seam area (weld seam contour in top view) and the CT evaluation measured the pore content related to the weld seam volume.

\section{RESULTS AND DISCUSSION}

The quantitative development of the influencing variables with indication of the standard deviation on the porosity measured by $\mathrm{x}$-ray image evaluation is shown in Figures 3 and 5 .
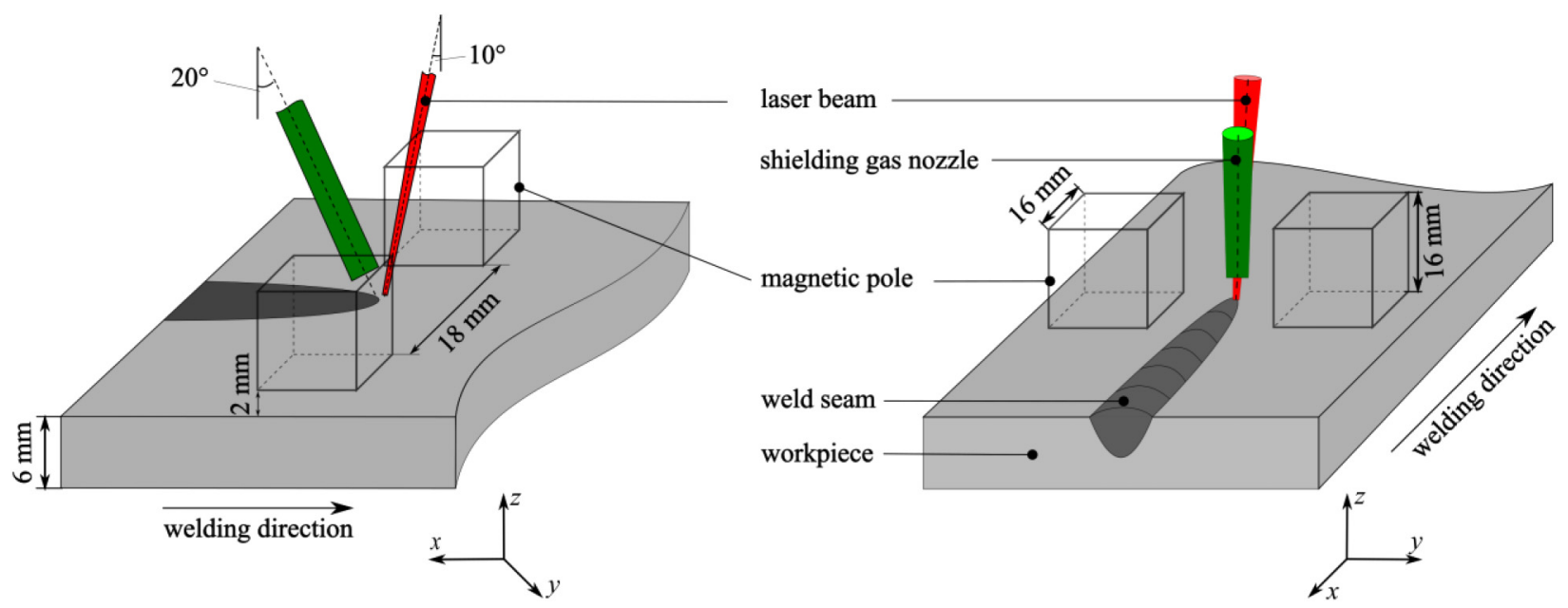

FIG. 2. Schematic illustration of the experimental setup with the most important geometrical parameters. 
TABLE IV. Coded factors and the composition of the CCD plan for determining the response (porosity ratio).

\begin{tabular}{|c|c|c|c|}
\hline \multirow[b]{2}{*}{ Parameters } & \multicolumn{3}{|c|}{ Coded levels } \\
\hline & -1 & 0 & 1 \\
\hline$P_{\mathrm{L}}(\mathrm{kW})$ & 3 & 4 & 5 \\
\hline $\mathrm{x}_{2} \quad u_{\text {weld }}\left(\mathrm{m} \mathrm{min}^{-1}\right)$ & 2 & 3 & 4 \\
\hline \multirow[t]{2}{*}{$B(\mathrm{mT})$} & 0 & 175 & 350 \\
\hline & \multicolumn{3}{|c|}{ Coded CCD } \\
\hline Experiment & $\mathrm{x}_{1}$ & $\mathrm{x}_{2}$ & $\mathrm{x}_{3}$ \\
\hline 1 & 1 & 1 & 1 \\
\hline 2 & 1 & 1 & -1 \\
\hline 3 & 1 & -1 & 1 \\
\hline 4 & 1 & -1 & -1 \\
\hline 5 & -1 & 1 & 1 \\
\hline 6 & -1 & 1 & -1 \\
\hline 7 & -1 & -1 & 1 \\
\hline 8 & -1 & -1 & -1 \\
\hline 9 & 0 & 0 & -1 \\
\hline 10 & 0 & 0 & 1 \\
\hline 11 & 0 & 1 & 0 \\
\hline 12 & 0 & -1 & 0 \\
\hline 13 & 1 & 0 & 0 \\
\hline 14 & -1 & 0 & 0 \\
\hline 15 & 0 & 0 & 0 \\
\hline 16 & 0 & 0 & 0 \\
\hline 17 & 0 & 0 & 0 \\
\hline 18 & 0 & 0 & 0 \\
\hline 19 & 0 & 0 & 0 \\
\hline 20 & 0 & 0 & 0 \\
\hline
\end{tabular}

Figure 3 demonstrates for the experiments with $\mathrm{AlSi12}(\mathrm{Fe})$ that an increase of the magnetic flux density $B$ leads to a reduction of the porosity from $12.4 \%$ at $0 \mathrm{mTorr}$ (welds without EM influence) to $3.9 \%$ at 350 mTorr. This corresponds to an improvement of $69 \%$. In contrast, an increase of the laser power $P_{\mathrm{L}}$ from 3 to $5 \mathrm{~kW}$ is associated with an increase of the porosity by $61 \%$, from $4.7 \%$ to $7.9 \%$. Considering the correlation of all influencing variables, a linear relationship is recognizable across the individual factor levels. The welding velocity $u_{\text {weld }}$ has no significant influence and leads to a

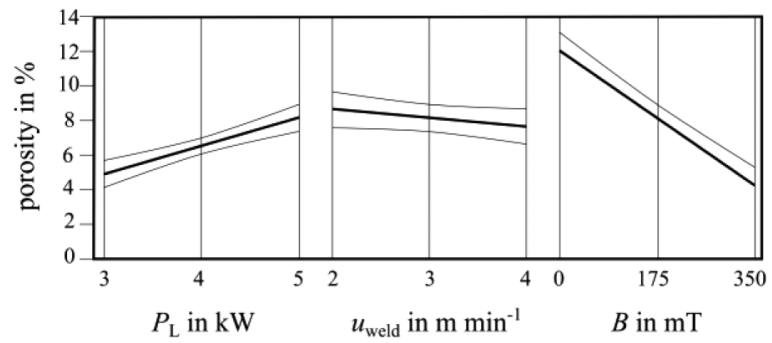

FIG. 3. Graphical representation of the relationship of the respective influencing factor on the porosity at AlSi12(Fe). slight decrease in porosity. This is also expressed in the calculation of porosity according to the multiple linear regression equation,

$$
\hat{y}=6.5505+1.6006 \times P_{L}-0.4957 \times u_{\text {weld }}-3.8816 \times B .
$$

The coefficient of determination $\mathrm{R}^{2}$, which represents the quality of the regression model and test results, is 0.927 and thus very good. The value of the standard deviation of the model, root mean square (RMS) value, is 0.9419 . The probability of error for the hypothesis that there is a so-called "Lack of Fit" is 0.656 . This means that the size of the model error can be neglected.

To illustrate the effect of the two essential parameters for AlSi12(Fe), a contour line chart is used (see Fig. 4). It can be clearly seen that the pore content falls linearly with decreasing laser power and increasing flux density. The pore content can be reduced to such an extent by the magnetic flux density alone, i.e., independent of the laser power and the welding speed, that the weld seams can be classified in valuation group C of the DIN EN ISO 13913-2 standard.

In order to be able to classify and evaluate the results at the die-cast aluminum alloy, the same experiments were performed on wrought alloy AlMg3, which thus serves as a reference material. Comparing the progressions of laser power and welding velocity with regard to pore content, it can be seen that this is qualitatively and quantitatively similar to the die casting alloy (see Fig. 5).

With rising laser power, the measured porosity doubles, starting with $4.2 \%$ at $3 \mathrm{~kW}$. The influence of the welding velocity is negligible, just like within the tests of the die casting. In contrast to $P_{\mathrm{L}}$ and $u_{\text {weld }}, B$ is not linear and shows quadratic relation. Quantitatively, the porosity level is significantly lower than with die casting.

It drops from $7.1 \%$ for welds without EM influence (at 0 mTorr) to approximately $2 \%$ at 350 mTorr, which corresponds to a reduction of approximately $72 \%$. The equation of the regression model for the material AlMg3 is as follows:

$$
\begin{aligned}
\hat{y}= & 6.3011+2.0843 \times P_{L}+0.4676 \times u_{\text {weld }}-2.5728 \times B \\
& -1.1665 P_{L} \times B-1.7461 B^{2} .
\end{aligned}
$$

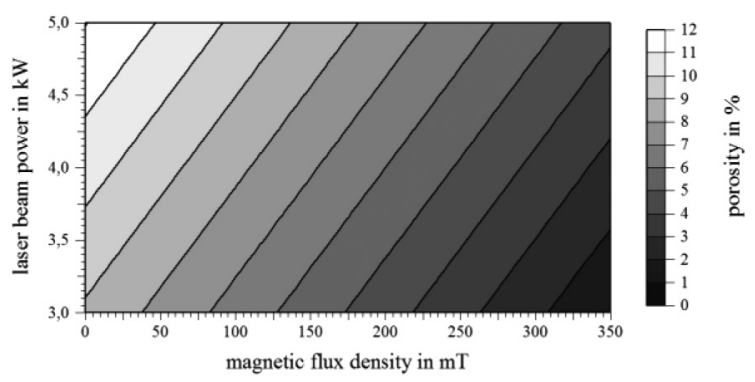

FIG. 4. Representation of the effect on porosity as a function of the relationship between magnetic flux density and laser power in the tests with AlSi12(Fe), calculated based on the statistical correlations. 


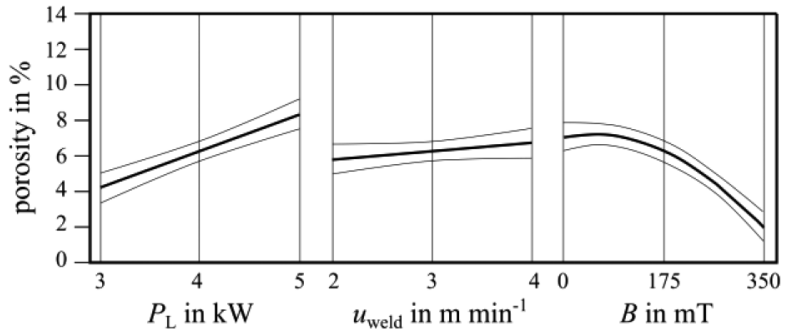

FIG. 5. Graphical representation of the relationship of the respective influencing factor on the porosity at AlMg3.

It can be seen that, in addition to the linear influences of the three influencing factors, the interaction between laser power and magnetic flux density as well as the quadratic term of the magnetic flux density is also important. In this case, $\mathrm{R}^{2}$ has a value of 0.932 . The RMS value here is 0.849 . The size of the model error can be neglected here too, since the probability of error for the hypothesis that there is a lack of fit is 0.378 . Thus, the porosity value is again significantly influenced here by $P_{\mathrm{L}}$ and $B$. Therefore, a contour line plot is created based on the statistical correlations, which illustrates the pore content depending on these two variables (see Fig. 6). For experiments up to a $B$ field of 175 mTorr, the laser power is the dominant factor by which the porosity is determined. From a value of $B=175 \mathrm{mTorr}$, the quadratic influence of the magnetic flux density becomes noticeable and the porosity drops to a level below $3 \%$, independent of $P_{\mathrm{L}}$. These welding results can be classified in evaluation group B of DIN EN ISO 13919-2. Due to the differences between the materials with regard to the qualitative course of the magnetic flux density, it is assumed that this influences the weld

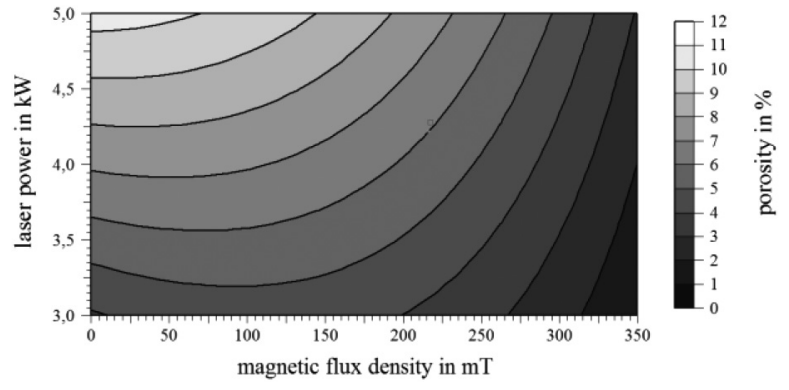

FIG. 6. Representation of the effect on porosity as a function of the relationship between magnetic flux density and laser power in the experiments with AlMg3, calculated based on the statistical correlations.

pool geometry, respectively, weld pool flow. The die casting alloy clearly shows a linear decrease of the pore content, a quadratic decrease in the wrought alloy, which is only noticeable from a value greater than 175 mTorr. This aspect must be investigated in the following by means of simulations. An increase of the laser power leads mainly to an increase of the welding depth. Therefore, a higher magnetic flux density seems to be necessary in order to be able to remove pores from deeper regions of the weld pool by increasing the initiated electromagnetic pressure.

The increase of $B$ alone leads to a porosity decrease of approximately $70 \%$, independent of the material. The findings show for subsequent welding tests on overlapping joints that the lowest possible laser power and a high magnetic flux density should be selected.

The evaluations carried out by means of x-ray images are further analyzed in detail with randomly selected CT images. The CT
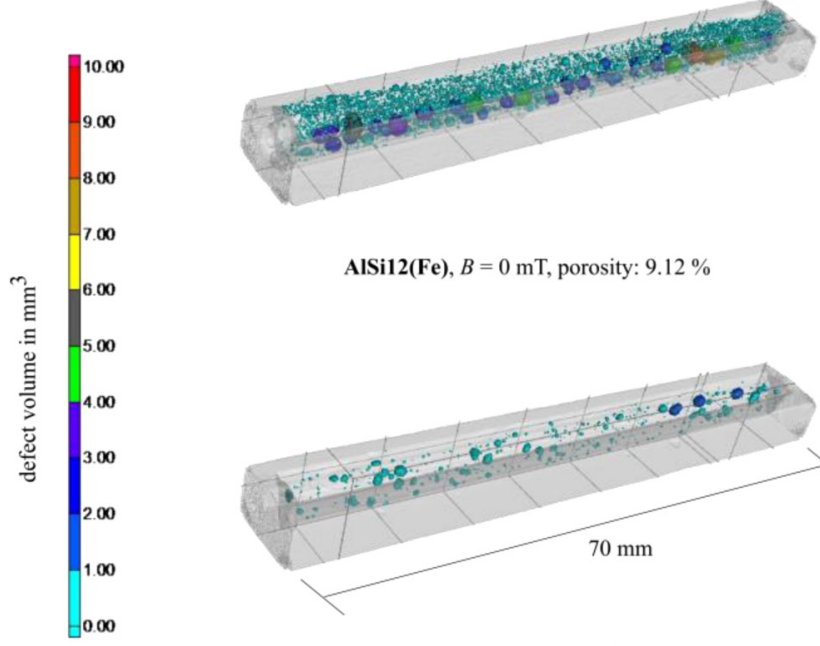

AlSi12(Fe), $B=0 \mathrm{mT}$, porosity: $9.12 \%$

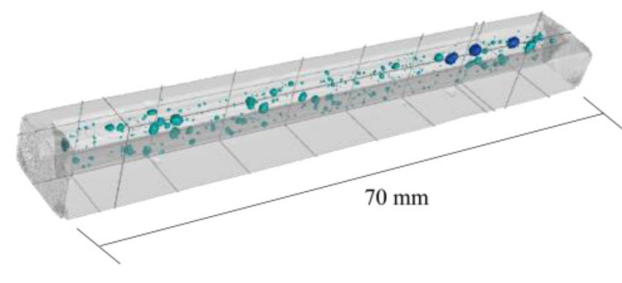

AlMg3, $B=0 \mathrm{mT}$, porosity: $2.2 \%$

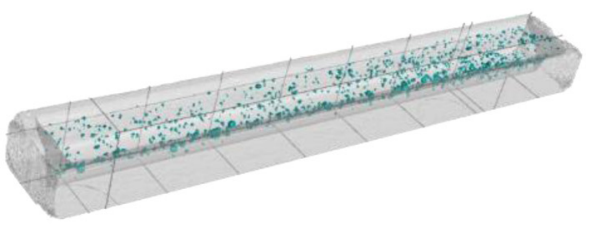

AISi12(Fe), $B=350 \mathrm{mT}$, porosity: $0.98 \%$

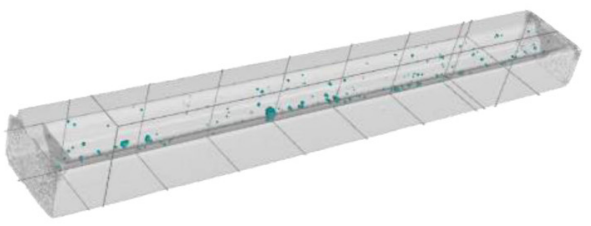

AlMg3, $B=350 \mathrm{mT}$, porosity: $0.37 \%$

FIG. 7. Comparison of selected CT images at constant laser power ( $5 \mathrm{~kW})$ and welding velocity $\left(2 \mathrm{~m} \mathrm{~min}^{-1}\right)$ of AlSi12(Fe) (above) and AlMg3 (below) with reference to the porosity measured at the weld seam volume. 
images qualitatively confirm the trend in terms of the findings previously obtained from x-ray images. The following CT images show the defect volumes for both materials with the same laser power $\left(P_{\mathrm{L}}=5 \mathrm{~kW}\right)$ and the same welding velocity $\left(u_{\text {weld }}=2 \mathrm{~m} \mathrm{~min}^{-1}\right)$ (see Fig. 7). In die casting, a defect volume of $9.12 \%$ can be seen without EM influence, which is successively reduced to a value of $0.98 \%$ as the $B$ field increases [Fig. 7 (above)]. This corresponds to an improvement of approximately $90 \%$. A total of 29 large pores in the range from 1 to $8.7 \mathrm{~mm}^{3}$ could be detected at $B=0 \mathrm{mTorr}$. These defect volumes can no longer be proven at $B=350$ mTorr. Here, the largest single pore has a defect volume of approximately $0.5 \mathrm{~mm}^{3}$. For AlMg3, the CT images for identical parameters are visualized in Fig. 7 (below). Here, the degree of reduction $(-83 \%)$ is at a similar level, from initially $2.2 \%$ to $0.37 \%$ at $B=350 \mathrm{mTorr}$. Four pores larger than $1 \mathrm{~mm}^{3}$ are contained in the CT image with $B=0 \mathrm{~m}$ Torr. At $B=350 \mathrm{~m}$ Torr, the largest single pore is $0.84 \mathrm{~mm}^{3}$ and the next smaller one is $0.24 \mathrm{~mm}^{3}$. The CT images were analyzed in more detail with regard to the defect volumes (see Figs. 8 and 9). Three volume groups were formed, and the number of pores for each group was counted. Figure 8 shows the number of pores corresponding to the defect volume classes for the die casting alloy. First, for welding without EM influence, a large number of pores is counted for each volume class, especially pores with a volume of more than $0.4 \mathrm{~mm}^{3}$ (46 counts). With a magnetic flux density of $350 \mathrm{mTorr}$, the number of pores can be significantly minimized, in this case to less than ten pores in the class up to $0.25 \mathrm{~mm}^{3}$ and to two remaining pores for the other two classes. Even with pore volumes in the range from 0.01 to $<0.1 \mathrm{~mm}^{3}$, the number of pores could be reduced from 836 (at $B=0$ mTorr) to 289 (at $B=350$ mTorr). The same trend can also be observed at

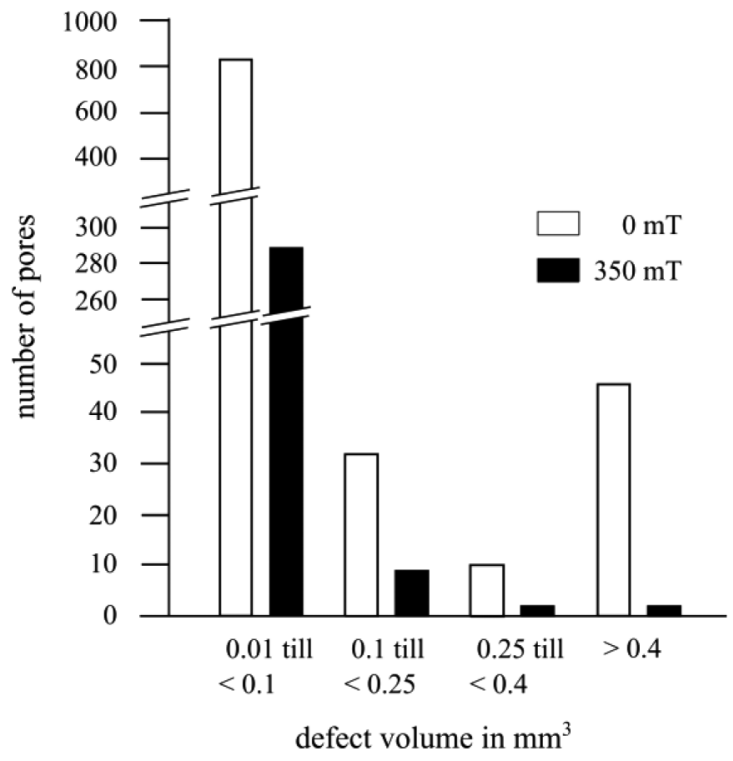

FIG. 8. Bar chart regarding the number of pores as a function of the defect volume for AISi12(Fe), based on the CT images in Fig. 7 (above).

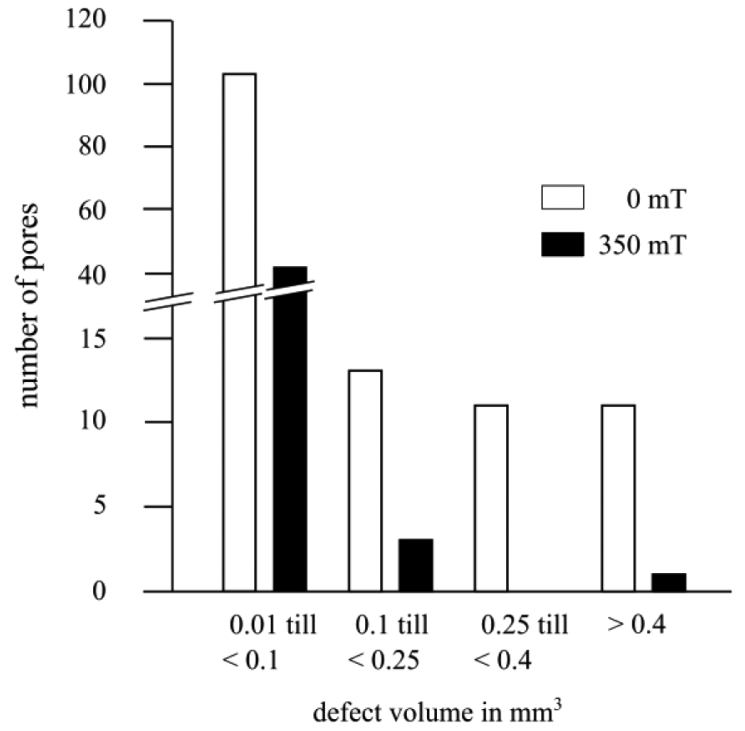

FIG. 9. Bar chart regarding the number of pores as a function of the defect volume for AIMg3, based on the CT images in Fig. 7 (below).

the wrought alloy in Fig. 9 with a reduction from 103 counts to 42 at $B=350 \mathrm{~m}$ Torr.

For the listed groups, the pores were eliminated, starting from more than ten pores without EM influence on less than three pores at $B=350$ mTorr.

Thus, a significant reduction of the pores can be determined for the parameter sets analyzed by means of CT images, both regarding their number and regarding the defect volume during laser beam welding. It is especially the case with wrought alloy, but this was expected due to the higher hydrogen content in AlSi12 $(\mathrm{Fe})$. Nevertheless, impressive results on a very good level are achieved by the EM support also in die casting.

\section{SUMMARY}

This paper describes a systematic investigation of the EM influenced laser beam welding of the aluminum die casting alloy AlSi12 $(\mathrm{Fe})$ in comparison to a reference material, a wrought aluminum alloy AlMg3. By using of a face centered CCD test plan, the influencing variables laser power, welding velocity, and magnetic flux density are varied with regard to their influence on the remaining porosity. The global pore fraction of the weld seams was analyzed by x-ray images with IMAGEJ. This enabled a qualitatively very good regression model to be derived for the respective material, which identifies the dominant influencing variables. The results proved, statistically verified, for the investigated parameter range, that

- the magnetic flux density is the main cause for the porosity reduction,

- the porosity rises with increasing laser power, and the porosity in the weld seams rises,

- the influence of the welding velocity is negligible, and 
- the porosity decreases due to the EM influence by approximately $70 \%$ compared to the unaffected welds. This effect is emphasized by the contour line charts, which illustrate the relationship between laser power and magnetic flux density.

With the exception of the quadratic influence of $B$ at the wrought alloy, the statistical correlation shows a linear development of the respective influence variables for both aluminum alloys. In order to investigate these deviations, further simulations with a focus on weld pool geometry and weld pool flow are to be performed. In addition, the welding results can be classified in accordance with DIN EN ISO 13919-2 in the highest evaluation group B for AlMg3 and in evaluation group $\mathrm{C}$ for $\mathrm{AlSi} 12(\mathrm{Fe})$ by applying a magnetic flux density of 350 mTorr. The analysis of the CT images at constant laser power and welding velocity allows a direct comparison both between the two alloys and also as a function of the magnetic flux density with regard to the number and size of pores. An increase in the magnetic flux density leads to a significant decrease in the number and volume of pores, which can be seen more clearly in wrought alloy than in die casting. Very acceptable results can be achieved for both materials and different welding parameters. This successfully demonstrates the desired process robustness and functionality of the EM system for practical applications. For subsequent investigations of overlap joints, the lowest possible laser power and a high magnetic flux density are recommended.

\section{REFERENCES}

${ }^{\mathbf{1}}$ F. Teichmann, S. Müller, and K. Dilger, "On the occurrence of weld bead porosity during laser vacuum welding of high pressure aluminium the castings," Proc. CIRP 74, 438-441 (2018).

${ }^{\mathbf{2}}$ H. Pries, M. Rethmeier, S. Wiesner, and H. Wohlfahrt, Laser- und Elektronenstrahlschweißen von Aluminium-Druckguss, DVS-Berichte Band 220 (DVS Verlag GmbH, Düsseldorf, 2002), pp. 219-223.

${ }^{3}$ N. Seto, S. Katayama, and A. Matsunawa, "Porosity formation mechanism and suppression procedure in laser welding of aluminium alloys," Weld. Int. 15, 191-202 (2001).

${ }^{4}$ M. Ruhstorfer, Rührreibschweißen von Rohren (Herbert Utz Verlag, Munich, 2012), Vol. 262.

${ }^{\mathbf{5}} \mathrm{M}$. Bachmann, A. Gumenyuk, and M. Rethmeier, "Welding with high-power lasers: trends and developments," Phys. Proc. 83, 15-25 (2016).

${ }^{6}$ D. Dittrich, A. Jahn, J. Standfuss, and E. Beyer, "Laser beam welding of atmosphere aluminum die cast material using high frequency beam oscillation and brilliant beam sources," J. Laser Appl. 29, 022425 (2017).

${ }^{7}$ A. Fritzsche, K. Hilgenberg, F. Teichmann, H. Pries, K. Dilger, and M. Rethmeier, "Improved degassing in laser beam welding of aluminum die casting by an electromagnetic field," J. Mater. Process. Technol. 253, 51-56 (2018).

${ }^{8}$ A. Fritzsche, K. Hilgenberg, F. Teichmann, H. Pries, and M. Rethmeier, "Electromagnetic porosity reduction in laser beam welding of die-cast aluminum alloy," in Lasers in Manufacturing (Wissenschaftliche Gesellschaft Lasertechnik eV (WLT) (Hrsg.), Munich, 2017).

${ }^{9}$ Z. T. Zhang, Q. T. Guo, F. Y. Yu, L. I. Jie, J. Zhang, and T. J. Li, "Motion behavior of non-metallic particles under high frequency magnetic field," Trans. Nonferrous Met. Soc. China 19, 674-680 (2009).

${ }^{10}$ Standard DIN EN ISO 13919-2:2001-12, Welding-Electron and Laser Beam Welded Joints-Guidance on Quality Levels for Imperfections-Part 2: Aluminium and Its Weldable Alloys (Beuth-Verlag, Berlin, 2001).

${ }^{11}$ V. Avilov, A. Schneider, M. Lammers, A. Gumenyuk, and M. Rethmeier, "Electromagnetic control of the weld pool dynamics in partial penetration laser beam welding of aluminium alloys," Int. Congr. Appl. Lasers Electro-Opt. 2012, 250-256 (2012).

${ }^{12}$ Standard DIN EN ISO 1706-2010-06, Aluminium and Aluminium AlloysCastings-Chemical Composition and Mechanical Properties, German version EN 1706:2010 (Beuth-Verlag, Berlin, 2010).

${ }^{13}$ Standard DIN EN 573-3:2013-12, Aluminium and Aluminium AlloysChemical Composition and Form of Wrought Products-Part 3: Chemical Composition and Form of Products (Beuth-Verlag, Berlin, 2013).

${ }^{14}$ R. G. Brereton, Chemometrics: Data Analysis for the Laboratory and Chemical Plant (Wiley, New York, 2003), p. 489.

\section{Meet the Authors}

André Fritzsche, born in 1987, received his M.Sc. in the field of mechanical engineering at the Technical University Berlin Institute. Since 2011, he has been a member of the department "Welding Technology" at BAM Federal Institute for Materials Research and Testing. Since 2015, he has been working as a research assistant at the same department. Currently, he is working in the field of electromagnetic influenced laser beam welding processes.

Professor Dr.-Ing. Kai Hilgenberg conducted his Ph.D. studies at the Chair of Metal Forming Technology at the University of Kassel until 2014. Afterward, he began working as team leader at BAM Federal Institute for Materials Research and Testing in the area of laser material processing. Since 2015, he has been holding a position as Junior Professor at the Institute of Machine Tools and Factory Management, Technical University Berlin.

Professor Dr.-Ing. Michael Rethmeier is with the BAM Federal Institute for Materials Research and Testing. He is the head of the division "Welding Technology." $\mathrm{He}$ is also heading the "Chair of Joining Technology" at the Institute of Machine Tools and Factory Management, Technical University Berlin and is division director of "Joining and Coating Technology" at the Fraunhofer Institute for Production Systems and Design Technology. His present research topics include, among others, innovative arc welding processes, high power laser beam welding, and numerical simulations in various welding processes. 